\title{
Sugar metabolism and developmental stages of rubber tree (Hevea brasiliensis L.) seeds
}

\author{
Genaina Aparecida de Souza ${ }^{a}{ }^{*}$, Denise Cunha Fernandes dos Santos Dias ${ }^{b}$, Thaline Martins Pimenta ${ }^{a}$, \\ Andrea Lanna Almeidaa, Edgard Augusto de Toledo Picolia ${ }^{a}$ Antônio de Pádua Alvarengac and José \\ Cleydson Ferreira da Silvad \\ a'Departamento de Biologia Vegetal, Universidade Federal de Viçosa, Campus Universitário, s/n, Viçosa, MG, 36570-000, Brazil \\ bepartamento de Fitotecnia, Universidade Federal de Viçosa, Campus Universitário, s/n, Viçosa, MG, 36570-000, Brazil \\ 'Empresa de Pesquisa Agropecuária de Minas Gerais, EPAMIG, Unidade Sudeste, Universidade Federal de Viçosa, Campus Universitário, s/n, Viçosa, \\ MG, 36570-000, Brazil \\ ¿Laboratório de Biologia Molecular de Plantas - BIOAGRO, Universidade Federal de Viçosa, Campus Universitário, s/n, Viçosa, MG, 36570-000, Brazil
}

\author{
Correspondence \\ *Corresponding author, \\ e-mail: genainasouza@yahoo.com.br
}

Received 1 June 2017;

revised 3 October 2017

doi:10.1111/ppl.12650
Changes in the concentration of sugars and sucrose metabolism enzymes can characterize the developmental stages of a seed. In recalcitrant species such as Hevea brasiliensis L., little is known about these changes. We aimed to evaluate the three main stages of development of rubber tree seeds - histodifferentiation, cell elongation and accumulation of reserves. The activities of acid and neutral invertases (E.C. 3.2.1.26) and sucrose synthase (EC 2.4.1.13), and the concentrations of reducing sugars (RS), total soluble sugars (TSS) and sucrose (Suc) were determined concomitantly with the histochemical and anatomical evaluation of seed structure. Histodifferentiation in rubber tree seeds occurs up to 75 days after anthesis (DAA). The concentration of RS is high and of Suc is low during seed histodifferentiation, which occurs along with a visible increase in the number of cell divisions. After that period, there is an increase in the concentration of Suc $\left(\mathrm{mg} \mathrm{g}^{-1}\right)$ and in the number and size of starch granules, and a decrease in the concentration of RS $\left(\mathrm{mg} \mathrm{g}^{-1}\right)$. At that point, cell elongation occurs. At $135 \mathrm{DAA}$, there is an inversion in the concentration of these two sugars and an increase in reserve accumulation. Thus, in seeds of the evaluated clone, the period up to 75 DAA is characterized as the histodifferentiation stage, while from that time up to 120 DAA the cell elongation stage takes place. The final stage of seed maturation and reserve accumulation begins at $135 \mathrm{DAA}$, and the seed, including the embryo, is completely formed at 175 DAA.

\section{Introduction}

Several steps are involved in seed development, such as cell division, histodifferentiation, maturation and desiccation. Proper occurrence of these steps is essential to ensure seed quality and survival (Pavithra et al. 2014). Anatomical and biochemical modifications occur orderly according to events inherent to the stage of development in which the seeds are.

Among these anatomical changes, structural alterations that facilitate dehydration are particularly relevant, such as the reduction in size and number of vacuoles and changes in the cell wall (Vicré et al. 2004). Such modifications are associated with seed maturation and

Abbreviations - DAA, days after anthesis; DAP, days after pollination; RS, reducing sugars; Suc, sucrose; SuSy, sucrose synthase; TSS, total soluble sugars. 
are closely related to orthodox seeds (Bryant et al. 2001, Barbedo et al. 2013). On the other hand, a lower proportion of polysaccharides and an increased number and size of vacuoles are observed in recalcitrant seeds like those of Inga vera, which indicates the occurrence of high metabolic activity in the embryo (Caccere et al. 2013).

Although orthodox seeds may alternate between stages of tolerance and sensitivity to desiccation, at early stages of development, when water content is high, seeds are sensitive to desiccation (Parcy et al. 1994). At the maturation stage, when water content is low, desiccation tolerance is induced in seeds. Throughout germination, desiccation tolerance is progressively lost (Nedeva and Nikolova 1997). Thus, during both development and germination, orthodox seeds have a recalcitrant behavior (Pereira et al. 2017).

Biochemical changes, such as variations in the contents of sugars and enzymes involved in seed metabolism, provide important information that allows for the understanding of seed development. Some authors associate the accumulation of oligosaccharides and sucrose (Suc) during seed development with the late maturation stage, in which seeds may or may not acquire desiccation tolerance (Leprince et al. 1993). Suc and the sugars of the raffinose series are considered efficient substances in stabilizing macromolecules and the membrane structure during seed desiccation (Leprince et al. 1993). In contrast, reducing sugars (RS) (glucose, fructose, galactose and maltose) are characteristic of tissues from desiccation-intolerant seeds (Horbowicz and Obendorf 1994). In addition, sugars can act as signaling molecules in gene regulation (Hartig and Beck 2006, Wang and Ruan 2013). Low Suc concentration stimulates basic processes, such as photosynthesis and nutrient transport, and inhibits development of the endosperm and embryo (Koch 2004). At high concentrations, Suc also inhibits basic functions, like photosynthesis, in source organs and stimulates growth and storage in sink organs and structures, like developing seeds (Wang and Ruan 2013).

Suc is the main sugar used for long-distance transport in plant tissues. In sink tissues, Suc may be either broken down into glucose (Glc) and fructose (Fru) by invertase or converted to UDP glucose (UDPG) and Fru by sucrose synthase (SuSy) (Wang and Ruan 2013). Suc hydrolysis is vital to plants, not only for carbon allocation, but also for triggering developmental signals in importing structures (Koch 2004). An example of the latter case is the triggering of cell division in the seed for endosperm and embryo formation. A large number of loci responding to sugar levels have been identified and shown to participate in various hormonal signals, like abscisic acid, ethylene, and cytokinins (Hartig and Beck 2006). This signaling role of sugars is even more prominent in light of its close relationship with different stages of plant development (Smeekens et al. 2010, Eveland and Jackson 2012).

In seeds, the role of sugars in molecular signaling is related to endosperm formation. The endosperm is formed earlier than the embryo due to a spatial concentration gradient of Glc, which is higher in the former (Nowack et al. 2007). Such difference in Glc concentration favors cell division in the endosperm during early seed development (Wang and Ruan 2012). After that, increased activity of enzymes like SuSy, followed by decreased activity of invertases, characterizes a change in metabolism that will further lead to the accumulation of reserves, to the detriment of the cell divisions that are necessary during early stages of seed development (Koch 2004).

In the present work, we studied the kinetics of sugar consumption and enzyme activity during development of the recalcitrant rubber tree seed. We chose this approach due to the lack of such information and to the commercial importance of the selected plant species. The study was performed concomitantly with the evaluation of seed histodifferentiation, in order to contribute to comprehending the development of recalcitrant seed. We aimed to address the following question: can sugar metabolism be used to define and characterize the seed developmental stages in Hevea brasiliensis, a recalcitrant species?

\section{Materials and methods}

\section{Plant material}

Plant material (fruits and seeds) was obtained from 50 plants of the RRIM 600 clone of $H$. brasiliensis L., rubber tree. Ovaries of flowers at anthesis and fruits at different stages were collected. Fruit development was monitored from anthesis to opening by date-labeling inflorescences. Samples were collected every 15 days starting from anthesis, except at 105 days after anthesis (DAA), due to unfavorable weather conditions. For growth analysis, we measured 50 seeds from 10 different plants and for moisture content 5 replications with 10 seeds. Samples for biochemical analyses were kept frozen at $-80^{\circ} \mathrm{C}$ until processing. Samples for microscopic analyses were fixed in an appropriate solution as described further below.

\section{Determination of starch and sugar concentration}

Crude extracts for determination of contents of starch, total soluble sugars (TSS) and RS were obtained from $1 \mathrm{~g}$ 
plant material ground in a mortar with liquid nitrogen (repeated 5 times). Extracts were obtained from $10 \mathrm{ml}$ of heated $\left(60-70^{\circ} \mathrm{C}\right) 80 \%$ ethanol after centrifuging at $2000 \mathrm{~g}$ for $10 \mathrm{~min}$, thrice. The supernatant was removed for quantification of TSS and RS. The pellet was dried for later quantification of starch by the method proposed by McCready et al. (1950). The reserved crude extract was used for determination of RS content by the method of Somogyi (Nelson 1944). Concentration of RS was determined in whole seeds and, whenever possible, separately in the embryo and in the endosperm. TSS content was determined by the phenol-sulfuric acid method proposed by Dubois et al. (1956), in a manner similar to the one adopted in starch quantification. Suc concentration was determined following Bonome et al. (2011), by obtaining the difference between the whole-seed contents of TSS and RS and multiplying it by the factor 0.95 (sucrose conversion factor). Sugar quantification in embryos separately from the endosperm was possible only from 120 DAA.

\section{Quantification of enzyme activity}

Extraction and evaluation of SuSy (EC 2.4.1.13) and invertase (E.C. 3.2.1.26), acid (Al) and neutral (NI) activities were carried out in five replications. For quantification of SuSy activity, plant material was ground in a mortar with liquid nitrogen, followed by addition of $0.1 \mathrm{~g}$ of sample and $200 \mu \mathrm{l}$ of extraction buffer solution ( $1 \mathrm{M}$ HEPES-KOH, $\mathrm{pH} 6.0 ; 100 \mu \mathrm{l}$ of $0.1 \mathrm{M} \mathrm{MgCl}_{2}$ ), $100 \mu \mathrm{l}$ of $0.1 \mathrm{M}$ UDP, and $400 \mu \mathrm{l}$ of $1.0 \mathrm{M} \mathrm{Suc}$, followed by completion with water to a final volume of $2000 \mu \mathrm{l}$. The assay was incubated in water bath at $25^{\circ} \mathrm{C}$ for $60 \mathrm{~min}$, after which it was transferred to ice to stop the reaction.

The activity of invertases was determined by the RS concentration (Miller 1959). For Al extraction, $0.2 \mathrm{~g}$ of material was added to $200 \mu$ l of $1 M$ sodium acetate buffer with $\mathrm{pH} 4.7,100 \mathrm{ml}$ of $0.1 \mathrm{M} \mathrm{MgCl}_{2}$ and $400 \mu \mathrm{l}$ of $1 \mathrm{M} \mathrm{Suc}$, followed by completion with water to $2000 \mu \mathrm{l}$. After that, samples were incubated in water bath at $37^{\circ} \mathrm{C}$ for $60 \mathrm{~min}$, after which the reaction was stopped by transferring the assay to ice. The same procedure was used for $\mathrm{NI}$ extraction, replacing the sodium acetate buffer solution with $0.1 \mathrm{M}$ phosphate buffer solution, $\mathrm{pH}$ 7.0. Moisture content was determined in an oven at $105 \pm 3^{\circ} \mathrm{C}$ for $24 \mathrm{~h}$ (Brasil 2009) with 5 seeds per evaluation time, and seed growth was monitored using a digital caliper with 50 seeds per time.

\section{Light microscopy}

Seeds collected every 15 days starting from anthesis were fixed in FAA (formaldehyde, glacial acetic acid, 50\% ethanol, 1:1:18, volume-volume) for $48 \mathrm{~h}$, stored in $70 \%$ ethanol, dehydrated in an ethanol series and embedded in 2-hydroxyethyl methacrylate (Historesin, Leica Instruments, Nußloch/Heidelberg, Germany). Cross sections $5-\mu \mathrm{m}$ thick were obtained with a rotary microtome (model RM2155, Leica Microsystems, Deerfield, IL) and stained with $0.05 \%$ toluidine blue, pH6.5 (O'Brien et al. 1964). Glass slides were mounted with synthetic resin (Permount, Fisher Scientific, Waltham, MA). Lugol reagent (Johansen 1940) was used for starch detection on sections of samples collected at 120, 135, 150 and 180 DAA. Five samples from each phase were evaluated with a total of 20 cuts per sample. For each cut, five fields were photographed and analyzed.

Image capture, documentation and analysis were performed using a light microscope (model AX70TRF, Olympus Optical, Tokyo, Japan) equipped with a U-photo system and a digital camera (model AxioCam HRc, Carl Zeiss, Jena, Germany). Samples from each collected period were then associated with the respective seed developmental stage.

\section{Results}

\section{Carbohydrate metabolism, enzymes of sucrose metabolism, and growth variables during seed development}

Rubber tree seeds had high initial water content during early development. Early growth, from 45 to 75 DAA, was intense. From 75 to 135 DAA, growth was slower, yet another stage of intense growth took place from 135 to 150 DAA (Fig. 1A). Moisture content decreased to $45-50 \%$ until the seeds dispersal, at 180 DAA (Fig. 1A). Concentrations of RS, TSS, and Suc changed along seed development. Concentration of RS increased up to $40.82 \pm 3.25 \mathrm{mg} \mathrm{g}^{-1} \mathrm{FW}$ at 75 DAA. In contrast, Suc concentration remained as low as $4.64 \pm 1.33 \mathrm{mg}$ $\mathrm{g}^{-1}$ FW at that period. After 75 DAA, Suc concentration increased, reaching $62.62 \pm 5.8 \mathrm{mg} \mathrm{g}^{-1} \mathrm{FW}$ at 175 DAA (Fig. 1C). At early stages of seed development, $\mathrm{Al}$ activity increased until $75 \mathrm{DAA}$, along with $\mathrm{NI}$, whose activity only slightly increased until then. At 75 DAA, Al activity decreased, and at 120 DAA such decrease was even more pronounced. On the other hand, SuSy activity remained constant up until 60 DAA; from that period, a substantial increase was observed in the activity of that enzyme, extending until the end of the seed developmental period. In fruits, a decline in the activity of all evaluated enzymes was observed after 75 DAA (Fig. 1D).

An increase in starch concentration was also observed along seed development (Fig. 1D). From 120 to 175 

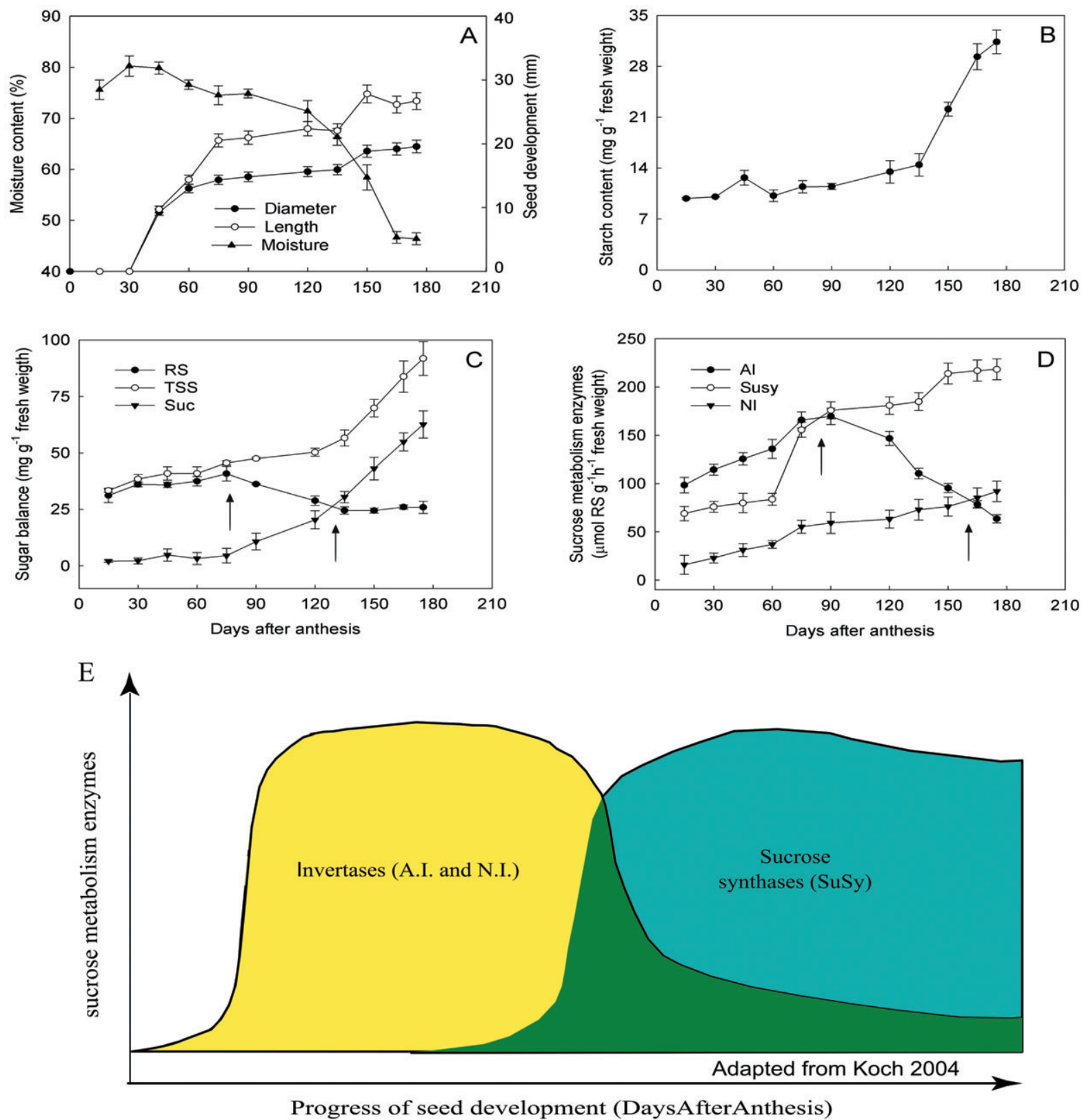

Fig. 1. Seed development in the rubber tree. (A) increase in growth, means $\pm S D, n=50$, and moisture content, means $\pm S D, n=5$. (B) $s t a r c h$ concentration, means $\pm S D, n=5$. (C) changes in contents of RS, TSS, and Suc, means $\pm S D, n=5$. (D) sucrose metabolism enzymes Al, SuSy, and NI, means $\pm S D, n=5$. (E) enzymatic activity patterns of invertases and sucrose synthases throughout seed development.

DAA, the increase in starch content is related to the increase in Suc concentration, since Suc can be stored temporarily in the form of starch, whose content showed no significant change in seeds until 120 DAA $\left(14.5 \pm 1.6 \mathrm{mg} \mathrm{g}^{-1} \mathrm{FW}\right)$. At that point, an increase in starch concentration was observed up until the end of seed maturation, at $175 \mathrm{DAA}$, when values of up to $31.4 \pm 1.6 \mathrm{mg} \mathrm{g}^{-1} \mathrm{FW}$ were detected (Figs 1B and 3).

\section{Seed development}

Embryo formation can be observed with the naked eye at 120 DAA. At that period, higher RS concentration was observed in the endosperm (18.46 $\left.\mathrm{mg} \mathrm{g}^{-1} \mathrm{FW}\right)$ than in the embryo (10.40 $\left.\mathrm{mg} \mathrm{g}^{-1} \mathrm{FW}\right)$. This difference decreased as seed development approached maturation. Prior to dispersal, RS concentration was approximately $10.97 \mathrm{mg}$ $\mathrm{g}^{-1} \mathrm{FW}$ in the endosperm and $14.97 \mathrm{mg} \mathrm{g}^{-1} \mathrm{FW}$ in 
the embryo (data not shown). Before 120 DAA, when the embryo would then develop, a space filled with an aqueous mass could be seen with the naked eye (Fig. 2). The biochemical constitution of that mass was not evaluated.

\section{Anatomical characterization of seed development}

The ovules of $H$. brasiliensis are bitegmic and crassinucellate. The outer integument is composed of four to five cell layers, while the inner integument consists of seven to nine layers. Both integuments have small cells with dense cytoplasm and a conspicuous nucleus. The multi-stratified nucellus is composed of voluminous, vacuolated cells (Fig. 3A). Few structural modifications occur in the integuments during early seed development. At $15 \mathrm{DAA}$, there is a slight increase in the number of tegmen cell layers. Nucellus and tegmen cells have small vacuoles, dense cytoplasm and evident nucleus, indicating mitotic activity (Fig. 3B). At 30 DAA, an increase in number of cells is observed in the tegmen and endosperm (Fig. 3C), which continues throughout seed development until 75 DAA, when mitotic activity is tightly reduced. At 45 DAA, tegmen (Fig. 3D) and endosperm (Fig. 3E) thicknesses are approximately twice as higher than at the previous stage. The increase in number of endosperm cells occurs mainly through division of cells from the outermost layers (Fig. 3F), while cell division in the tegmen occurs randomly. Mitotic activity ceases at 90 DAA, when no region with cells undergoing division can any longer be identified in the endosperm (Fig. 3J).

From 60 to $90 \mathrm{DAA}$, the exotegmen, a layer related to mechanical resistance in $\mathrm{H}$. brasiliensis seeds, develops. At 60 DAA, exotegmic cells are small, slightly elongated radially, and have dense cytoplasm and evident nucleus (Fig. 3A, B, G). Exotegmic cells undergo radial elongation at $75 \mathrm{DAA}$ (Fig. $3 \mathrm{H}$ ) and reach their final size at 90 DAA (Fig. 3I), when they then form a palisade. After 90 DAA, a secondary wall with lignin deposition is formed in exotegmic cells. From 90 DAA, seed development is characterized by expansion of integument and endosperm cells as well as by embryo growth. At 180 DAA, which corresponds to the mature-seed stage, endosperm cells are voluminous and have a single vacuole occupying the central cell region and a conspicuous nucleus (Fig. 3K). Cotyledon cells are also voluminous but their nuclei are not evident, yet they have several smaller-sized vacuoles (Fig. 3L). Embryonic-axis cells also have several small vacuoles, but unlike cotyledon cells they are characterized by the presence of a conspicuous nucleus and dense cytoplasm
(Fig. 3M), indicating the beginning of cell division in that region.

\section{Accumulation of starch}

Starch accumulation in storage tissues started at $120 \mathrm{DAA}$ and ended at $175 \mathrm{DAA}$, when the endosperm and embryo were already fully developed (Figs 1B and 3). Starch reserves were observed in the endosperm, cotyledons, and embryonic axis. From 135 DAA, starch accumulation significantly increased until the end of seed maturation, at 150 and 175 DAA. At 150 DAA, higher starch grain concentration was observed in the endosperm than in the embryo (Fig. 4A-C). An increased number and size of starch grains were observed at 175 DAA in all storage tissues (Fig. 4D-F).

\section{Discussion}

The higher RS concentration observed at the beginning of seed development may have resulted from Suc cleavage (Bonome et al. 2011). Several studies have shown higher concentrations of hexoses during early stages of seed development, correlating this with the promotion of cell division (Baud et al. 2002, Borisjuk et al. 2003) (Fig. 1C, D). This hypothesis is supported by the higher increase in cell number and more evident cell nuclei observed in such stages (Fig. 3A, B, F, H). Changes in the concentration of sugars contribute to our understanding of the developmental stage in which the seed is. In a study carried out with an unknown rubber tree clone from seed development to maturation, the authors observed a reduction in RS content in the endosperm (Bonome et al. 2011). Such reduction was more intense at 120 days after pollination (DAP), whereas the reduction in RS content observed in our study occurred at 90 DAA. This difference can be attributed to variations in the environmental conditions among experimental sites and to seed moisture content at each evaluated time (Fig. 1A). Moisture content was highest at the early periods and decreased throughout development. Water content (Barbedo et al. 2013) and the percentage of dry matter (Caccere et al. 2013) are considered good indexes for estimating physiological maturity of seeds. In addition to the variation in moisture content, variability in genetic features among the studied plants should also be taken into account. In the embryo, a significant increase in RS content was observed at 90 days in both studies (Fig. 1C).

Moisture content was used as a basis for comparison of the evaluated seed developmental stages, namely histodifferentiation, cell elongation, and accumulation of reserves. As previously mentioned, anatomical and 

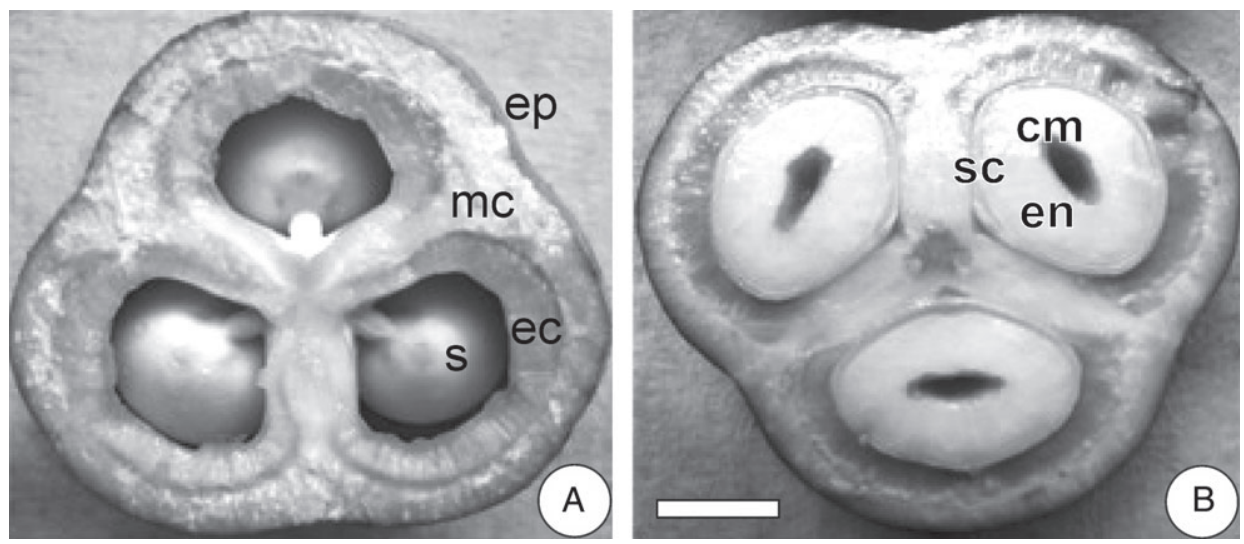

Fig. 2. Cross section of the rubber tree fruit $(A)$, showing the space where the embryo is formed $(B)$, which is initially occupied by a mass of gelatinous cells. sc, seed coat; en, endosperm; ep, epicarp; mc, mesocarp; ec, endocarp; s, developing seed; and cm, cell mass. Bar $=1 \mathrm{~cm}$.

biochemical modifications, like cell expansion and alteration in enzyme activity, were detected, and they may well depend on and be influenced by such moisture content.

The RS activity observed in the endosperm and embryo may be related to the role those sugars play in molecular signaling. This signaling commands earlier and faster formation of the endosperm by increasing glucose concentration in its formation region (Nowack et al. 2007). The increase in RS content in the embryo at the final stages of development may be attributed to the recalcitrant features of the studied species, since metabolism remains high during late maturation. Due to the presence of high moisture content even at late development, recalcitrant seeds sustain a high metabolism (Sershen et al. 2012b).

Such high metabolic activity is observed by the resumption of cell division in the embryonic axis of the analyzed seeds (Fig. 3M). This is in agreement with the report made by Farrant et al. (1992), who observed a high concentration of RS during late development of Avicennia marine seeds in addition to no reduction in moisture content. The authors associated this behavior with the rapid germination of recalcitrant seeds. The absence of preparatory events for desiccation - and consequently for cryptobiosis - may be related to the lack of modifications that are commonly observed in orthodox seeds. A higher number of smaller vacuoles occupying the cytoplasm (Pavithra et al. 2014) and higher accumulation of sugars with high molecular weight (Farrant et al. 1992) are both related to a higher desiccation tolerance. In $\mathrm{H}$. brasiliensis seeds, we observed few vacuoles occupying a large cell volume (Fig. 3K), similarly to what was reported by Pavithra et al. (2014). It should be emphasized that before 90 DAA no analysis was conducted in the embryo, as its small size hampered its separation with the naked eye; also, such separation was unpractical, as we needed to gather a sufficient sample amount to perform the analyses.

The relationship between the processes of histodifferentiation and sugar consumption is also worth commenting on. Contents of available Suc were low during seed histodifferentiation, which is in agreement with the expected mobilization and use of carbon backbones to supply the energy and redox power demanded by the processes involved. As Suc is the preferential carbon backbone used in photosynthate transport, we observed the presence of this sugar in differentiating tissues, whereas the observed contents of RS were low, probably due to the use of the hexose pool in cell metabolism.

In general, high levels of monosaccharides and low levels of oligosaccharides are found during early stages of seed development. In the final stages, monosaccharide content is reduced (Pavithra et al. 2014), characterizing metabolic changes that take place in preparation to a period of cryptobiosis. This phenomenon, however, is attributed to orthodox seeds; rubber tree seeds, on the other hand, do not undergo cryptobiosis, as they are recalcitrant. Possibly, changes in the contents of RS, TSS and Suc, as well as in the pattern of cell division, which is resumed at late seed development, occur with the purpose of ensuring fast germination after dispersal. Similar results in regard to the concentrations of these sugars have been reported to seeds of $H$. brasiliensis (Bonome et al. 2011), Inga vera (Caccere et al. 2013), and Pongamia pinnata (Pavithra et al. 2014), all of which are recalcitrant species.

Germination in recalcitrant seeds begins immediately after dispersal, which in the case of our study could be observed by the aforementioned resumption of cell 

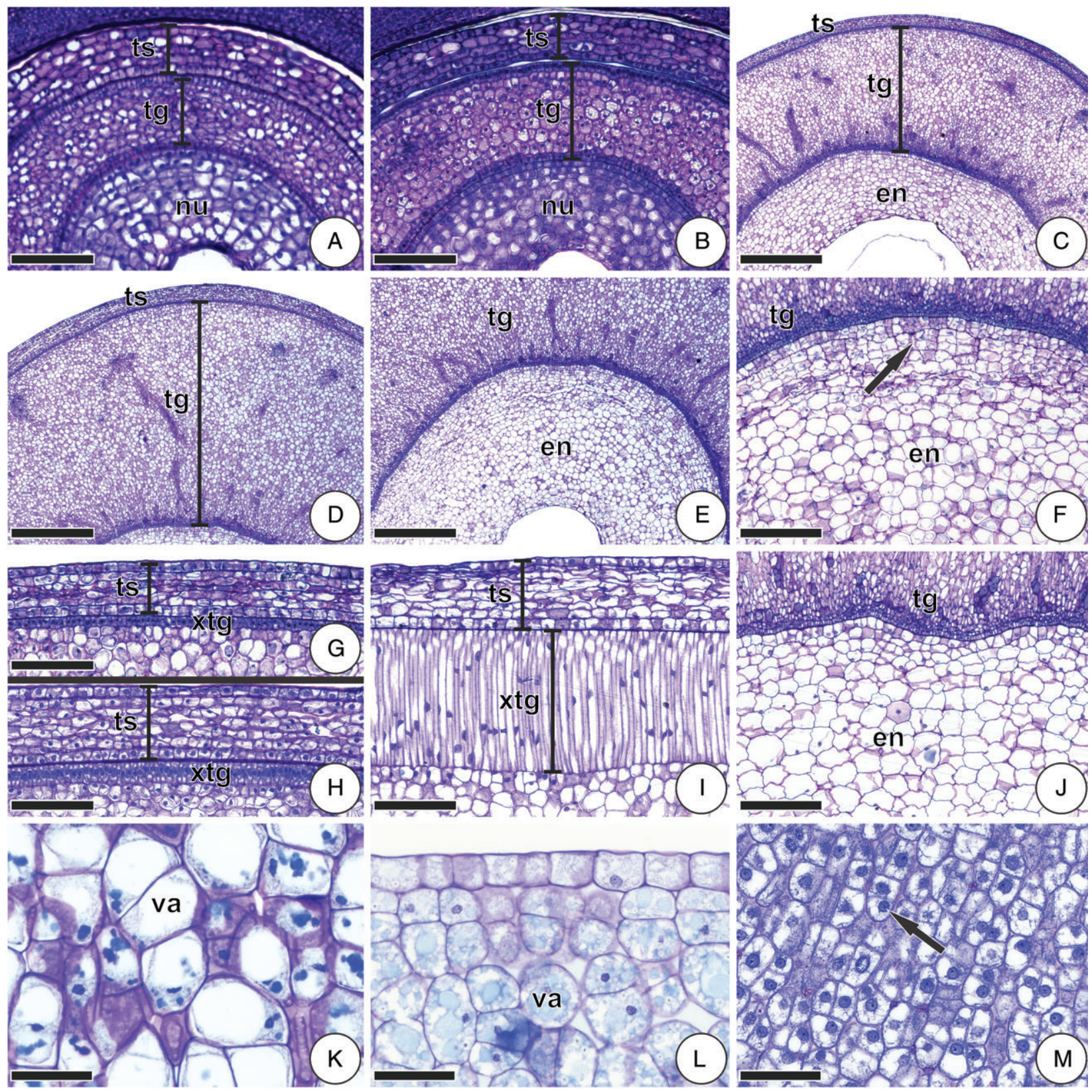

Fig. 3. Photomicrographs of cross sections of the ovule (A) and seeds of Hevea brasiliensis at 15 (B), $30(C), 45(D, E), 60(F, G), 75(H), 90(I$, $\mathrm{J})$, and $180(\mathrm{~K}-\mathrm{M}) \mathrm{DAA} . \mathrm{A}-\mathrm{F}$, development of the integuments and endosperm. $\mathrm{F}$, detail of the endosperm at $60 \mathrm{DAA}$, showing the region with intense cell division (arrow). G-I, cell differentiation in the exotegmen. J, detail of the endosperm at 90 DAA; no cell undergoing division was observed. $\mathrm{K}-\mathrm{M}$, storage tissues in mature seeds. $\mathrm{K}$, endosperm. L, cotyledon. $\mathrm{M}$, embryonic axis, with cells having evident nucleus and dense cytoplasm (arrow). en, endosperm; nu, nucellus; ts, testa; tg, tegmen; va, vacuole; xtg, exotegmen. Bars $=100 \mu \mathrm{m}(\mathrm{A}, \mathrm{B}, \mathrm{G}, \mathrm{H}, \mathrm{I}), 500 \mu \mathrm{m}(\mathrm{C}-\mathrm{E}), 200 \mu \mathrm{m}(\mathrm{F}, \mathrm{J})$, $50 \mu \mathrm{m}(\mathrm{K}-\mathrm{M})$.

division. In addition, we observed a small number of vacuoles occupying a large portion of the intracellular space (Fig. 3K). In Inga vera seeds, not only a slight reduction in the concentration of RS but also high metabolic rates were observed throughout the seed maturation stage and at the end of seed development. This denotes an absence of the reduction in metabolism that usually precedes seed dispersal, which is characteristic of recalcitrant species (Caccere et al. 2013).

Increased Suc concentration has a positive effect on seed formation and maturation (Koch 2004, Wang and Ruan 2013). The more expressive increase in 


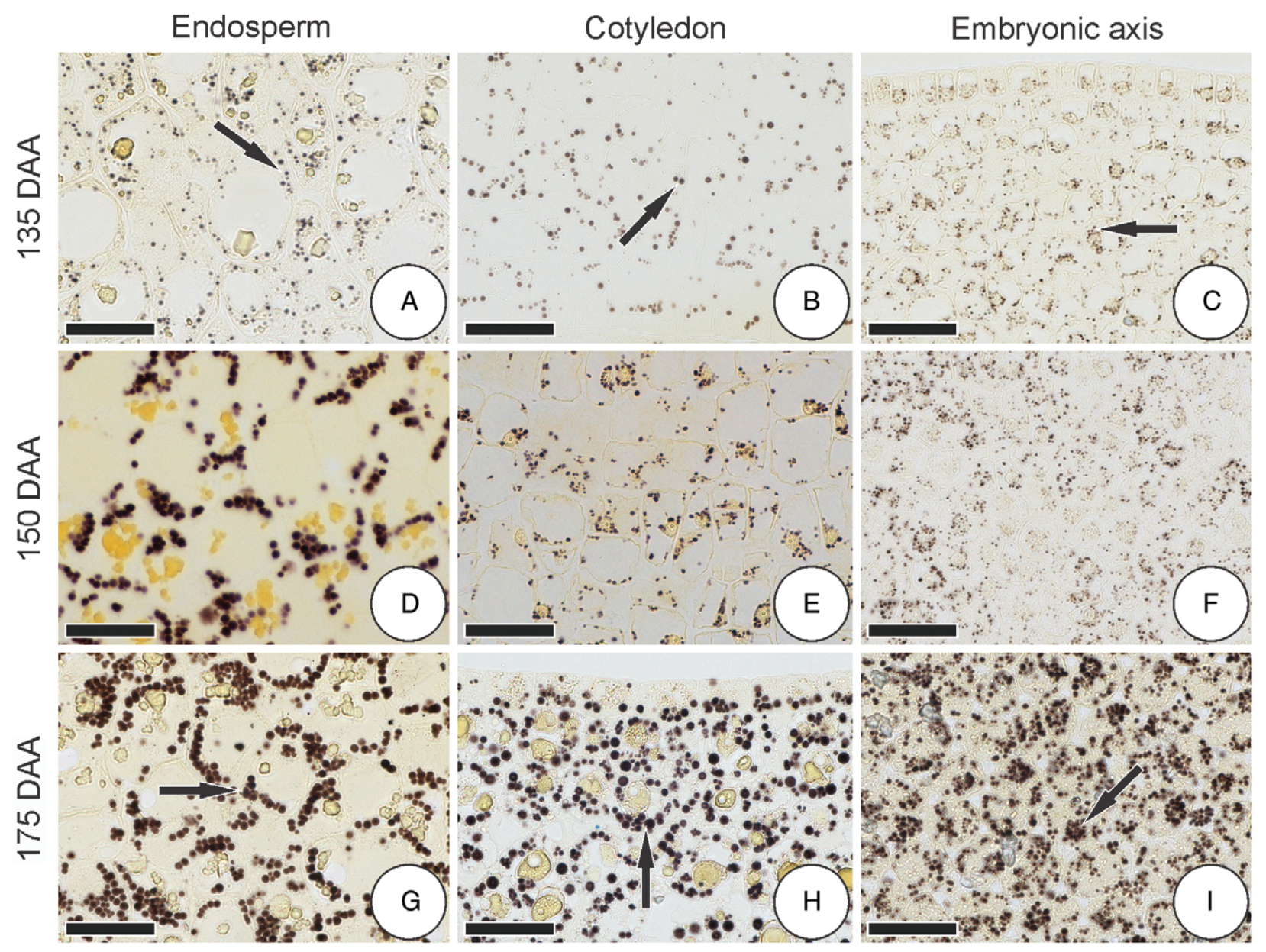

Fig. 4. Photomicrographs of cross sections of Hevea brasiliensis seeds at $135(A-C), 150(D-F)$, and $175 D A A$. Sections were treated with the Lugol reagent. The arrows indicate the starch bodies, showing an increase in the amount and intensity of the staining. Bars $=150 \mu \mathrm{m}$.

concentrations of Suc and TSS at 120 DAA was possibly due to a higher energy demand by the seed, which resulted in the accumulation of reserve compounds such as starch. Suc is widely associated with seed maturation and may be stored temporarily in the form of starch (Koch 2004). The enzyme SuSy plays a role in directing carbon flow to cell wall biosynthesis during late developmental stages. A major role attributed to this enzyme is converting the imported Suc into UDP-glucose (UDPG), which is then transformed to hexose-phosphates and ADPG, the latter of which is necessary for starch biosynthesis. In addition, SuSy has been suggested to be involved, at least in part, in the direct conversion of sucrose into starch biosynthesis-related ADPG in both autotrophic and heterotrophic cells (Figs 1B, C and 4). Sugars, besides providing carbon for cell growth, may also act as signaling molecules and play a role as expression regulators of different genes (Smeekens et al. 2010, Eveland and Jackson 2012, Wang and Ruan 2013).
During embryo development in legume crops, glucose was related to increased mitosis (Borisjuk et al. 2003), suggesting the existence of a relationship between hexoses and the cell cycle. Similar results were observed in our study, in which higher RS contents coincided with higher increase in cell number until 75 DAA (Figs 1C and $3 \mathrm{~A}-\mathrm{F})$. After that period, the rate of cell division decreased (Fig. 3J), increasing again in later periods near dispersal, also along with an increase in cell division in the embryonic axis and cotyledons (Fig. 3L and M).

The relationship between sugars and cell division control is reported to function in the modulation of gene expression of D-cyclin, a protein involved in the regulation of cell cycle (Gaudin et al. 2000). Thus, with the higher RS concentration observed during early rubber tree seed development, increased histodifferentiation and mitotic activity were also to be expected. This was confirmed by the observed dense cytoplasm and evident nuclei, as well as by the increase in cell number 
in the tegmen and endosperm (Fig. 3B and C). Higher Suc concentration at 120 DAA is related to late maturation, cell elongation, and accumulation of reserves (Koch 2004, Rolland et al. 2006, Bonome et al. 2011). Sugars, when acting as molecular signals of the synthesis of seed structures, promote differential tissue formation, leading to earlier and faster formation of the endosperm than of the embryo (Nowack et al. 2007) due to a spatial gradient of Glc concentration in the former toward the latter. Such difference in Glc concentration favors cell division in the endosperm during early seed development (Wang and Ruan 2012). Higher RS concentration in the embryo than in the endosperm was also observed in rubber tree seeds at 135 DAA (data not shown). Before that period, separation of embryo and endosperm samples was not possible, as then only a gelatinous mass was observed in the site where the embryo would further develop. This gelatinous mass became increasingly viscous up until the embryo was formed (Figs 2A-C, E and 3).

Inversion in the contents of RS, TSS and Suc has also been observed by Bonome et al. (2011). Change in the concentrations of these sugars along the different stages of seed development is attributed to the activity of sucrose metabolism enzymes (i.e. AI, NI and SuSy) (Rolland et al. 2006, Bonome et al. 2011). Inversion in the activity of Al and SuSy at 75 DAA is the landmark for the end of the histodifferentiation stage and the beginning of the maturation (cell elongation) stage. This hypothesis is reinforced by the fact that the increase in number of cells in the tegmen and endosperm occurred up to that time point (Fig. 3A-F), while at 90 DAA no such increase was observed (Fig. $3 \mathrm{~J}$ ). In addition, at the end of seed development, accumulation of reserves was detected (Fig. 4).

Several studies have shown that the shift from the histodifferentiation stage to the stage of accumulation of storage material and seed maturation is affected by sugar signaling in cells, as mentioned above. The transition between stages occurs due to a decrease in the expression and activity of invertases and an increase in SuSy activity, which affects the Suc/Glc balance, favoring Suc concentration (Wang and Ruan 2013). There is also evidence of a relationship between high activity of invertases and high hexose/sucrose concentration during early stages of seed development in rice (Hirose et al. 2002). This relationship may be associated with higher mitotic activity at early development due to the participation of invertases and to the balance of sugars that signal cell division.

In contrast, subsequent to the increase in SuSy activity, the aforementioned signaling changes favored the increase in contents of Suc and other reserve compounds (Fig. 1D). Similar results were reported by Bonome et al.
(2011) for rubber tree seeds, yet with increasing AI activity up until 95 DAP followed by a marked decline at 120 DAP. Furthermore, the authors also detected an increase in SuSy activity at 95 DAP and also reported an inversion in the activity of these enzymes at 100 DAP. In the case of our study, such inversion occurred at 75 DAA (Fig. 1D), which explains the observed changes in mitotic activity of tissues (Fig. 3) and in concentration of sugars (Fig. 1C).

The relationship between the decline in concentration of RS such as Glc and decreased mitotic activity in legume embryos was observed by Borisjuk et al. (1998) through the high-resolution histographical mapping technique. According to the authors, such relationship should be largely attributed to the decrease in gene expression of invertases. The activity of NI observed until 150 DAA was always lower than that of Al. This only changed at 165 and $175 \mathrm{DAA}$, when the activity of these enzymes inverted, although no reduction in RS contents was then observed. These data corroborate those reported by Bonome et al. (2011), also to rubber tree seeds. These authors also observed an increase in the amount of reserve material in the endosperm at a similar period. This was associated with the previously reported role of sugars as signals during seed development (Eveland and Jackson 2012, Wang and Ruan 2013).

We suggest that, in the case of the clone studied herein, the reserve accumulation stage begins at 135 DAA, with accumulation increasing after 150 DAA (Figs 1B and 4), when the embryo may still be at late stages of formation. Thus, the inversion in the rates of $\mathrm{NI}$ and $\mathrm{Al}$ activity that occurred at $75 \mathrm{DAA}$ is associated with a reduction in RS concentration and an increase in concentrations of TSS and sucrose, such decrease can be associated with starch accumulation at that period (Weschke et al. 2000). These metabolic changes are strongly related to the developmental stage in which the seed is and are regulated by the sugars present at each stage (Koch 2004). The increase in starch content may also be associated with a possible preparation for germination. Seeds need rapid energy availability; however, lipid breakdown is slower and demands higher energy resources. Structural changes were also observed, such as the increase in size of vacuoles from cotyledon cells, after which such organelles occupied a large portion of the cell volume. These changes may be an adaptation to accommodate the increased amount of reserve material, as represented by the increase in number and size of starch granules. This increase was evidenced in the comparison among histochemical images of starch granules in samples from 135, 150 and 175 DAA (Fig. 4).

Increased starch concentration is related to enzymatic activity of SuSy, from the Suc metabolism, which leads 
to a change in the use of carbon for starch synthesis in plastids. High gene expression for SuSy synthesis also coincides with rapid starch filling in rice grains (Wang and Ruan 2013). Similar results were also observed by Pavithra et al. (2014) and Sangwan et al. (2010) in P. pinnata seeds. Caccere et al. (2013) also detected the same in $I$. vera seeds, as evidenced by the observed increase in size and number of starch grains in the embryonic axis and cotyledons, similarly to what we observed in our study.

Although starch is not the main reserve of rubber tree seeds, the observed accumulation of reserve material indicates seed maturation. In that case, the Suc produced can be temporarily stored in the form of starch and be later used as a source of carbon for the synthesis of other reserve compounds such as proteins and lipids (Andriotis et al. 2010), or even as a source of energy in the cell metabolism or during germination.

Thus, the formation cycle of the rubber tree seeds used in this study is complete at 175 DAA. Rubber tree seeds are governed by changes in the activities of enzymes from the Suc metabolism, which directly influence the proportion of sugars present at each developmental stage. These sugars regulate cell metabolism, signaling the triggers that regulate morphogenetic differentiation during seed development. In addition, there is a close relationship between the balance of sugars, sucrose metabolism enzymes, and the developmental stage in which the seeds are. The interactions among these variables are associated with the signaling of the end of the histodifferentiation stage and the beginning of the stage of reserve accumulation and seed maturation.

\section{Conclusions}

Seed developmental stages in the rubber tree are related to the concentration and type of sugar present in the seeds. The stages of histodifferentiation, cell elongation and reserve accumulation can be defined based on the metabolism of sugars and related enzymes.

The histodifferentiation stage generally takes place from 75 to 90 DAA, followed by the cell elongation stage, which lasts until $120 \mathrm{DAA}$, and the largest reserve accumulation stage, which begins at 135 DAA. The seed is completely formed at 175 DAA.

\section{Author contributions}

G. A. S., D. C. F. S. D., A. L. A., A. d. P. A. and E. A. T. P. drafted the entire manuscript. T. M. P. and J. C. F. $\mathrm{S}$. edited the manuscript, the figures and collaborate on data collection and statistical analysis. All authors read corrected and approved the manuscript in its final form.
Acknowledgements - The authors acknowledge FAPEMIG, $\mathrm{CNPq}$ and EPAMIG.

\section{References}

Andriotis VME, Pike MJ, Kular B, Rawsthorne S, Smith AM (2010) Starch turnover in developing oilseed embryos. New Phytol 187: 791-804

Barbedo CJ, Centeno DC, Ribeiro RCLF (2013) Do recalcitrant seeds really exist? Hoehnea 40: 583-593

Baud S, Boutin JP, Miquel M, Lepiniec L, Rochat C (2002) An integrated overview of seed development in Arabidopsis thaliana ecotype WS. Plant Physiol Biochem 40: $151-160$

Bonome LTS, Moreira SAF, Oliveira LEM, Sotero AJ (2011) Metabolism of carbohydrates during the development of seeds of the Brazilian rubber tree [Hevea brasiliensis (Willd. Ex Adr. de Juss) Muell.-Arg.] Acta Physiol Plant 33: $211-219$

Borisjuk L, Walenta S, Weber H, Mueller-Klieser W, Wobus U (1998) High-resolution histographical mapping of glucose concentrations in developing cotyledons of Vicia faba in relation to mitotic activity and storage processes: glucose as a possible developmental trigger. Plant J 15: 583-591

Borisjuk L, Rolletschek H, Wobus U, Weber H (2003) Differentiation of legume cotyledons as related to metabolic gradients and assimilate transport into seeds. J Exp Bot 54: 503-512

Bryant G, Koster KL, Wolfe J (2001) Membrane behaviour in seeds and other systems at low water content: the various effects of solutes. Seed Sci Res 11: 17-25

Brasil, Ministério da Agricultura, Pecuária e Abastecimento. Regras para análise de sementes. Ministério da Agricultura, Pecuária e Abastecimento (2009). Secretaria de Defesa Agropecuária, Brasília, 395. Caccere R, Teixeira SP, Centeno DC, Ribeiro RCLF, Braga MR (2013) Metabolic and structural changes during early maturation of Inga vera seeds are consistent with the lack of a desiccation phase. J Plant Physiol 170: $791-800$

Dubois M, Gilles KA, Hamilton JK, Rebers PA, Smith F (1956) Colorimetric method for determination of sugars and related substances. Anal Chem 28: 350-356

Eveland AL, Jackson DP (2012) Sugars, signalling, and plant development. J Exp Bot 63: 3367-3377

Farrant J, Pammenter JNW, Berjak P (1992) Development of the recalcitrant (Homoiohydrous) seeds of Avicennia marina: anatomical, ultrastructural and biochemical events associated with development from histodifferentiation to maturation. Ann Bot 70: 75-86

Gaudin V, Lunness PA, Fobert PR, Towers M, Riou-Khamlichi C, Murray JAH, Coen E, Doonan JH (2000) The expression of D-cyclin genes defines distinct developmental zones in snapdragon apical meristems 
and is locally regulated by the cycloidea gene. Plant Physiol 122: 1137-1148

Hartig K, Beck E (2006) Cross talk between auxin, cytokinins, and sugars in the plant cell cycle. Plant Biol (Stuttg) 8: 389-396

Hirose T, Takano M, Terao T (2002) Cell wall invertase in developing rice caryopsis: molecular cloning of OsCIN1 and analysis of its expression in relation to its role in grain filling. Plant Cell Physiol 43: 452-459

Horbowicz M, Obendorf RL (1994) Seed desiccation tolerance and storability: dependence on flatulence-producing oligosaccharides and cyclitols - review and survey. Seed Sci Res 4: 385-405

Johansen DA (1940) Plant Microtechnique. McGraw Hill Book, New York

Koch K (2004) Sucrose metabolism: regulatory mechanisms and pivotal roles in sugar sensing and plant development. Curr Opin Plant Biol 7: 235-246

Leprince O, Hendry GAF, Mckersie BD (1993) The mechanisms of desiccation tolerance in developing seeds. Seed Sci Res 3: 231-246

McCready RM, Guggolz A, Silveira V, Owens HS (1950) Determination of starch and amylase in vegetables; application to peas. Analyt Chem 22: 1156-1158

Miller GL (1959) Use of dinitrosalicylic acid reagent for determination of reducing sugar. Anal Biochem 31: 426-428

Nedeva D, Nikolova A (1997) Desiccation tolerance in developing seeds. Bulgarian. J Plant Physiol 23: 100-113

Nelson NA (1944) Photometric adaptation of the Somogy method for the determination of glucose. J Biol Chem 153: 375-380

Nowack MK, Shirzadi R, Dissmeyer N, Dolf A, Endl E, Grini PE, Schnittger A (2007) Bypassing genomic imprinting allows seed development. Nature 447: 312-315

O'Brien TP, Feder N, Mccully ME (1964) Polychromatic staining of plant cell walls by toluidine blue. Protoplasma 59: 367-373
Pavithra HR, Gowda B, Shivanna MB (2014) Biochemical changes in the composition of developing seeds of Pongamia pinnata (L.) Pierre. Ind Crop Prod 53: 199-208

Parcy F, Valon C, Raynal M, Gaubier-Comella P, Delseny M, Giraudat J (1994) Regulation of gene expression programs during Arabidopsis seed development: roles of the $\mathrm{ABI} 3$ locus and of endogenous abscisic acid. Plant Cell 6: 1567-1582

Pereira WVS, Faria JMR, José AC, Tonetti OAO, Ligterink W, Hilhorst HWM (2017) Is the loss of desiccation tolerance in orthodox seeds affected by provenance? S Afr J Bot 112: 296-302

Rolland F, Baena-Gonzales E, Sheen J (2006) Sugar sensing and signaling in plants: conserved and novel mechanisms. Annu Rev Plant Biol 57: 675-709

Sangwan S, Rao DV, Sharma RA (2010) A review on Pongamia pinnata (L.) Pierre: a great versatile leguminous plant. Nat Sci 8: 130-139

Sershen, Varghese B, Pammenter NW, Berjak P (2012) Cryo-tolerance of zygotic embryos from recalcitrant seeds in relation to oxidative stress - a case study on two amaryllid species. J Plant Physiol 169: 999-1011

Smeekens S, Ma J, Hanson J, Rolland F (2010) Sugar signals and molecular networks controlling plant growth. Curr Opin Plant Biol 13: 274-279

Vicré M, Farrant JM, Driouich A (2004) Insights into the cellular mechanisms of desiccation tolerance among angiosperm resurrection plant species. Plant Cell Environ 27: 1329-1340

Wang L, Ruan YL (2012) New insights into roles of cell wall invertase in early seed development revealed by comprehensive spatial and temporal expression patterns of GhCWIN1 in cotton. Plant Physiol 160: 777-787

Wang L, Ruan YL (2013) Regulation of cell division and expansion by sugar and auxin signaling. Plant Sci 4: 1-9

Weschke W, Panitz R, Sauer N, Wang Q, Neubohn B, Weber H, Wobus U (2000) Sucrose transport into barley seeds: molecular characterization of two transporters and implications for seed development and starch accumulation. Plant J 21: 455-467 